\title{
PARINAUD'S SYNDROME SECONDARY TO THROMBOEMBOLISM FROM MYOCARDIAL INFARCTION ASSOCIATED WITH MYELOFIBROSIS
}

\author{
Paulo Roberto A. Rosa', Karla B. Mendonça $a^{2}$, Luiz M.F. Maduro3, \\ Armando Jorge Monnerat de Lemos ${ }^{4}$, Monica Cordeiro de Barros ${ }^{5}$, Gustavo Ventura Couto 6 , \\ Paulo Cesar de Souza Santos ${ }^{6}$, Alexandre de Oliveira Deslandes ${ }^{6}$, Alexandre Araujo Cruz ${ }^{6}$
}

Cerebrovascular disease is one of the main causes of death in Brazil. The main risk factors are arterial hypertension, diabetes, dyslipidemia and tabagism. Among the infrequent or subdiagnosed causes, we call attention to thrombolic diseases.

The Parinaud syndrome (PS) is defined as a upward paresis of vertical gaze by mesencephalon lesion, having as a main cause the pineal gland tumors'. Occurrence of ophthalmoplegias in cerebrovascular diseases is common in brain stem lesions by impairment of cranial nerves nuclei and pathways like the medial longitudinal fasciculus. However, we have found in literature review few cases of stroke as PS etiology.

We present a case of PS causaed by thalamic infarction due to a thrombolic syndrome. The patient's partner signed an informed consent.

\section{CASE}

A 57 years-old-woman, yellow, home worker, entered the emergency room with complaint of 48 hours-atypical headache,

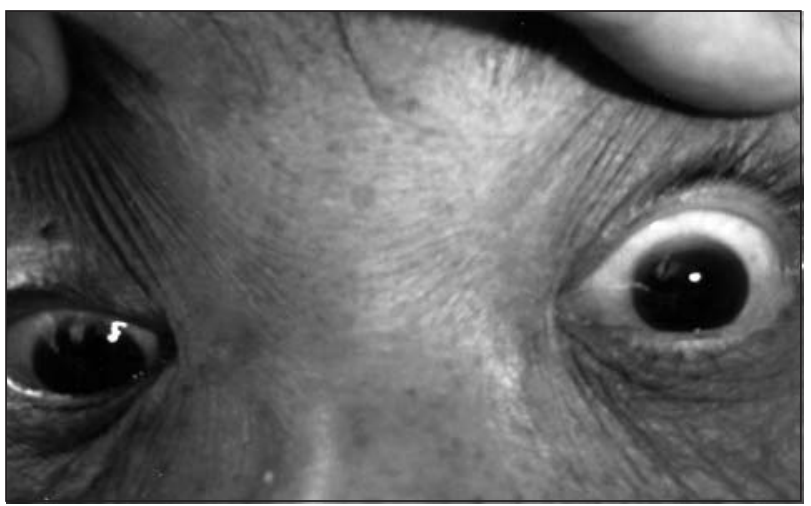

Fig 1. Upper gaze. followed by vomit, diplopia and difficulties in moving the right upper limb. She denied any other symptoms but a slight fatigue. Asthma crise were present in her previous history. She denied tabagism and alcoholism. Her family history was positive for diabetes mellitus and there was no cardiovascular disease report.

On neurological exam, she was confused, with right brachial monoparesis and tactile and painful hypoesthesia. We did not observe meningismus. Fundoscopy did not reveal alterations. The ocular mobility assessment showed vertical gaze paresis, with predominance of upper gazer, convergence paresis (Figs 1-2). The pupillary examination presented anisocory with left pupillary dilation, diminished photomotor reflex and consensual preservation. The vestibulococlear reflex was bilaterally normal. The other cranial nerves had no alterations. The patient was eupneic, with clear lungs, arterial pressure of $140 \times 80$ $\mathrm{mmHg}$ and heart rate of 76 beats per minute (bpm), regular cardiac rhythm in two periods, without heart bruits.

A CT scan of the brain did not revealed hemorrhage or infarction. MRI was performed, demonstrating in FLAIR and T2 sequences a signal increase in thalamus and in a small left teg-

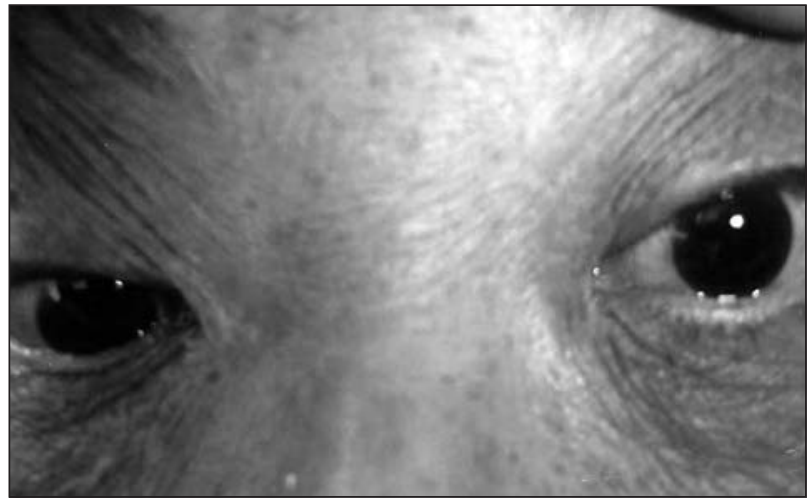

Fig 2. Down gaze.

SÍNDROME DE PARINAUD SECUNDÁRIA A TROMBOEMBOLISMO POR INFARTO DO MIOCÁRDIO ASSOCIADOS A MIELOFIBROSE

Hospital São Lucas, Nova Friburgo RJ, Brazil: 'Neurologist, Professor of Human Physiology, Universidade Estácio de Sá, Nova Friburgo RJ, Brazil; ${ }^{2}$ Hematologist; ${ }^{3}$ Cardiologist; ${ }^{4}$ Neurosurgeon; ${ }^{5}$ Patologist; ${ }^{6}$ Cardiovascular Surgeon.

Received 28 July 2008, received in final form 20 October 2008. Accepted 28 November 2008.

Dr. Paulo Roberto Alves Rosa - Avenida Alberto Braune 167 / 503 - 28613-001 Nova Friburgo RJ - Brasil. E-mail: prarosa@terra.com.br 


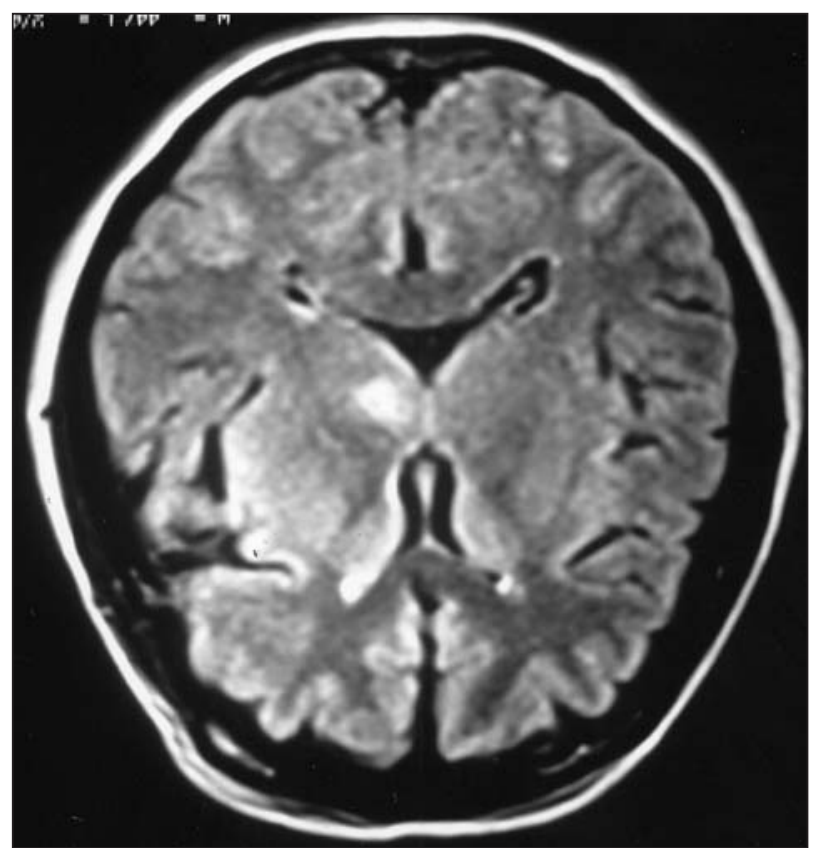

Fig 3. FLAIR sequence.

ument portion, suggesting acute vascular injury. There were hypersignal focuses on the subcortical white matter compatible to microangiopathy (Fig 3).

The hemogram presented $53 \%$ hematocrit and 699000 platelets. During cardiac investigation, her electrocardiogram demonstrated signals of inactive zone in anterior wall. The enzymatic profile was normal. The echocardiogram showed extensive akinesia in left ventricle and intracavitary thrombus. Cineangiocoronariographic exam demonstrated obstruction of the anterior interventricular artery, with signs of thrombus in distal portion. Just after the evaluation, polymyalgia and polyarthralgia of small and medium joints took place. In this occasion, Creative protein was $12 \mathrm{mg} / \mathrm{dL}$, with all the other rheumatic activity proofs negative. The serological tests for syphilis and AIDS were also negative.

The patient was submitted to a myocardial revascularization, thrombectomy and aneurysmectomy. She left the hospital with an oral anticoagulant and an investigation was put forward for the possibility of myeloproliferative disease. A myelogram was performed, which revealed myelofibrosis.

\section{DISCUSSION}

In 1883, Henri Parinaud, considered the father of the French ophthalmology, described three types of eye vertical paralysis: paralysis that affects upper gaze, lower gaze and both of them. According to Parinaud, the nuclei of the oculomotor nerves would be preserved in these paralyses. The PS is also known as the syndrome of the cerebral aqueduct, pretectal syndrome or posterior commissural syndrome. The complete version of PS presents with paralysis of vertical upper gaze, and less frequently of lower gaze, mydriasis, absence of light pupillary reaction and incapacity of ocular convergence. Some main causes of PS are pineal tumors, mesencephalus and cerebellum neoplasias, and demyelinizant, infectious and vascular diseases ${ }^{2,3}$.

The control pathways for vertical gaze are not well defined. Lesions on the mesencephalic reticular formation are described, including the posterior commissural nucleus (Darkschewitsch), the rostral interstitial nucleus of the medial longitudinal fasciculus, the Cajal interstitial nucleus and the posterior commissure ${ }^{3,4}$. Nevertheless we found only one work documenting three cases of thalamic infarction with vertical gaze impairment ${ }^{4}$.

Although cardiovascular disease is commonly associated to encephalic lesions, we found few cases correlated with PS. Verghese et al. described an unexpected case of PS of embolytic etiology in patient with patent foramen ovale ${ }^{5}$. In the present case, we point the occurrence of a thrombolic syndrome with overwhelming characteristics, simultaneously with an acute coronary disease.

Several deaths by acute myocardial infarction (AMI) occur before hospitalization, with 40 to $60 \%$ of the cases happening in initial hours after symptoms onset. The majority of these deaths are caused by lethal ventricular arrhythmias, which indicates the importance of a precocious access for an adequate treatment. In $20 \%$ of the cases of AMI, patients are oligosymptomatic or they can present no symptoms ${ }^{6,7}$. Considering the few cardiac symptoms and the normal enzymatic profile of the presented patient, we can suppose that the cardiac event occurred some days before hospitalization.

The myelofibrosis is a myeloproliferative disease that seldom presents evident clinical signs and symptoms. In general, diagnosis is made by hemogram and platelets measure. In some cases they evolve with hepatoesplenomegalia, leading to abdominal symptoms. In our report, the patient had a suspicious diagnosis by the evidences of polycythemia and thrombocytosis ${ }^{8}$.

The simultaneous occurrence of collagenosis and myeloproliferative diseases is described, however it is rare. In the present report, we investigated the possibility of collagenosis because of the levels of C-reative protein and the occurrence of polyarthralgia and polymyalgia. Nevertheless, the research is not conclusive for the diseases studied ${ }^{9}$.

We conclude that in stroke cases the investigation of thrombolic syndromes is indispensable, when well-defined risk factors are not present like arterial hypertension, diabetes and tabagism. Besides we consider uncommon the occurrence of PS in the semiological context of cerebrovascular diseases. 


\section{REFERENCES}

1. Adams RD, Victor M. Principles of neurology, $6^{\text {th }}$ Ed. New York: McGraw Hill, 1997:229.

2. Costa MF, Santos V, Pimentel MLV, et al. Síndrome de Parinaud e sinal de Collier: manifestação neurológica inicial em paciente HIV-1 positivo. Arq Neuropsiquiatr 1999;57:876-880.

3. Moguel-Ancheita S, Ruiz-Morfín I, Pedraza-Jacob M. Síndrome de Parinaud associado a otros estrabismos. Cir Ciruj 2006;74:147-151.

4. Clark JM, Albers GW. Vertical gaze palsies from medial thalamic infarctions without midbrain involvement. Stroke 1995;26:1467-1470.
5. Verghese S, Nair SB, Keep J. An unusual case of stroke in a young patient. Emerg Med J 2007;24:10.

6. Callif RM. Acute ischemic syndromes. Med Clin N Am 1995;79: 999-1024.

7. Smith SC JR, Blair SN, Criqui MH et al. AHA Consensus Panel Statement J Am Coll Cardiol 1995;26:292-294.

8. Barosi G. Myelofibrosis with myeloid metaplasia: diagnostic definition and prognostic classification for clinical studies and treatment guidelines. J Clin Oncol 1999;17:2954.

9. Bistue R, Gallo de Sprazzato ME, Scognamillo CD, et al. Coexistencia de mielofibrosis y colagenopatia. Medicina (B. Aires) 1990;50:248-250. 